\title{
COMPARISON OF POSTOPERATIVE CORNEAL ASTIGMATISM IN PHACOEMULSIFICATION AND MANUAL SMALL INCISION CATARACT SURGERY
}

\author{
NAYANTARA NAIR, DIVYA N. *, V. PANIMALAR, A. VEERAMANI, BINDU BHASKARAN \\ Department of Ophthalmology, Saveetha Medical College, Chennai, Tamil Nadu, India \\ Email: nairnayantara99@gmail.com
}

Received: 10 Jul 2020, Revised and Accepted: 08 Sep 2020

\begin{abstract}
Objective: Globally a significant proportion of treatable blindness is caused by cataract, especially in India and southeast Asia. Treatment of cataract is surgical correction with intraocular lens implantation. The main drawback of surgical correction is induction of postoperative astigmatism in patients. The aim of this study was to compare the degree of astigmatism in manual small incision cataract surgery and phacoemulsification 3 mo postoperatively
\end{abstract}

Methods: The study was a retrospective case study on postoperative corneal astigmatism after cataract surgery. It was conducted in a tertiary care hospital in Thandalam, Tamil Nadu. A total of 100 patients were selected and divided into two groups, group A (=50) underwent phacoemulsification and group B $(=50)$ underwent manual small incision cataract surgery. Preoperative astigmatic status of the patients was noted from patient records. Both groups were evaluated 3 mo postoperatively using automated keratometry. The data collected was analyzed using Microsoft Excel Independent T test, p< 0.05 was considered statistically significant. Power of the study was $80 \%$ with an alpha error of $5 \%$.

Results: Mean postoperative astigmatism at 3 mo was $0.91 \pm 0.255 \mathrm{D}$ and $0.34 \pm 0.110 \mathrm{D}$ due to manual small incision cataract surgery and phacoemulsification, respectively.

Conclusion: Postoperative astigmatism was greater in manual small incision cataract surgery than phacoemulsification. Improvement in preoperative astigmatism was seen in patients who underwent superotemporal incision phacoemulsification

Keywords: Cataract, Superior incision, Superotemporal incision, SIA, 3 mo, 2.8 mm incision, 5.5 mm incision

(C) 2020 The Authors. Published by Innovare Academic Sciences Pvt Ltd. This is an open access article under the CC BY license (http://creativecommons.org/licenses/by/4.0/) DOI: http://dx.doi.org/10.22159/ijcpr.2020v12i6.40295. Journal homepage: https://innovareacademics.in/journals/index.php/ijcpr

\section{INTRODUCTION}

In India, cataract accounts for $62.6 \%$ of blindness, followed by uncorrected refractive errors (19.7\%), glaucoma (5.8\%) and surgical complications (1.2\%). A 2002 study estimated 3.8 million Indians go blind from cataract per year [1]. Indian eye camps provide manual small incision surgery, a faster, low-cost alternative to phacoemulsification. In 2012, India achieved a cataract surgical rate of 6000 [2]. During 2016-2017, 64,81,435 cataract surgeries were performed with 95\% IOL implantation [3].

The drawback of MSICS is significant postoperative corneal astigmatism. Postoperative astigmatism depends on incision size, shape, site of incision and preoperative astigmatism [4].

Our study compares postoperative corneal astigmatism three months after MSICS and phacoemulsification, using automated keratometry.

\section{MATERIALS AND METHODS}

This study was a retrospective study conducted in a tertiary care hospital in Thandalam, Tamil Nadu, between January and March 2020. Patients who underwent Manual small incision cataract surgery (MSICS) and Phacoemulsification procedures were evaluated 3 mo postoperatively to determine the degree of total postoperative corneal astigmatism. Sample size of the study was 100 patients, further divided into two groups, A and B. Group A underwent phacoemulsification and Group B underwent MSICS. The average incision size used in MSICS was $5.5 \mathrm{~mm}$ made and in phacoemulsification it was $2.8 \mathrm{~mm}$. In MSICS superior incision was used and in Phacoemulsification a super temporal incision was used. Written informed consent was obtained from each patient or their guardian and preoperative astigmatic status of patients were noted from patient records. Both groups were evaluated 3 mo postoperatively using Bausch and Lomb automated keratometry. All postoperative cataract patients who underwent MSICS or Phacoemulsification, of all ages, willing to participate in the study were included in the study. With the exclusion of patients with systemic diseases like diabetes mellitus, hypertension etc, corneal abnormalities, traumatic and complicated cataract, and other causes of defective vision aside from cataract. Patients having undergone previous ocular surgery on the same side were also excluded from the study.

\section{Statistical analysis}

The data collected were analysed using Microsoft Excel Independent T-test, where $\mathrm{p}<0.05$ is considered as statistically significant. Sample size $(n=100)$ was calculated using convenient sampling, using a study by Bhandari et al. in Loni in 2019 as the reference study. Analysis of data was done using the power of study as $80 \%$ and an alpha error of $5 \%$. Results were tabulated in the form of frequency tables and bar graphs.

\section{RESULTS}

Data collected in the study was divided into two groups, group A and group $B$, according to the procedure undergone by the patient. Group A comprised of 17 males and 33 females and group B had 21 males and 29 females. Table 1 depicts the age and sex distribution among the patients in both groups.

Prior to surgery, in group A 48\% of patients had 0-0.5D of cylindrical power, whereas in group B $62 \%$ of patients had a cylindrical power between $0-0.5 \mathrm{D}$. Postoperatively among both groups, $64 \%$ of group A patients were observed to have $0-0.5 \mathrm{D}$ cylindrical power and $58 \%$ of group B were found to have 1-2D cylindrical power. Analysis of data in both groups shows mean preoperative astigmatism was $0.44 \pm 0.417 \mathrm{D}$ and mean postoperative astigmatism was $0.94 \pm 0.641 \mathrm{D}$. Degree of preoperative and postoperative astigmatism in groups A and B were recorded and are depicted in tables 2 and 3. 
Table 1: Age and sex distribution in group $A$ and $B$

\begin{tabular}{|c|c|c|c|c|}
\hline \multirow[t]{2}{*}{ AGE } & \multicolumn{2}{|l|}{ Group A $(n=50)$} & \multicolumn{2}{|c|}{ Group B $(n=50)$} \\
\hline & Male & Female & Male & Female \\
\hline & No. (\%) & No. (\%) & No. (\%) & No $(\%)$ \\
\hline $61-70$ & 18 & 52 & 22 & 38 \\
\hline $71-80$ & 16 & 14 & 20 & 20 \\
\hline TOTAL & $34 \%$ & $66 \%$ & $42 \%$ & $58 \%$ \\
\hline
\end{tabular}

In this study it was observed that $64 \%$ of MSICS patients and $70 \%$ of patients undergoing phacoemulsification were under $70 \mathrm{y}$ of age (fig. 1 ).

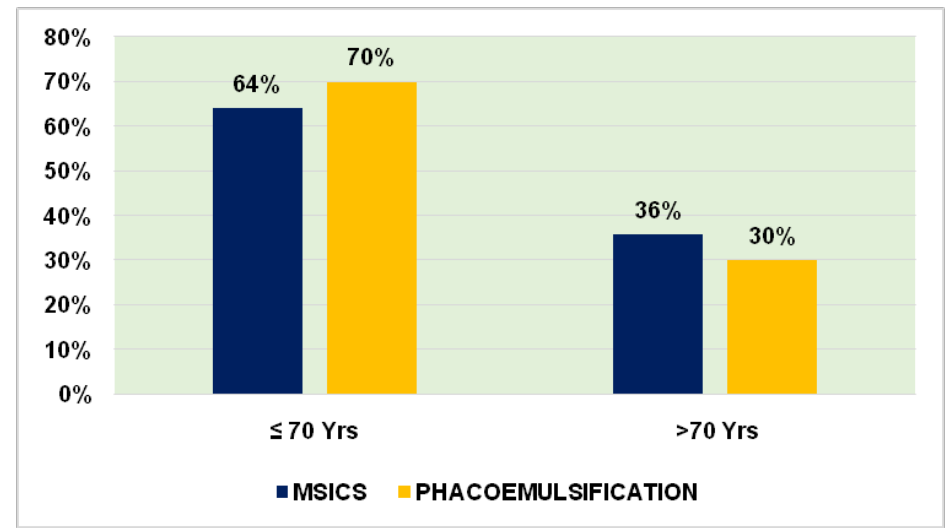

Fig. 1: Age distribution of patients undergoing phacoemulsification and MSICS in percentage

Table 2: Percentage of patients with preoperative astigmatism in group $A$ and $B$

\begin{tabular}{lll}
\hline Cylindrical power & Group A (\%) & Group B (\%) \\
\cline { 2 - 3 } & $\mathbf{N = 5 0}$ & N=50 \\
\hline & No.(\%) & No.(\%) \\
0 D & 28 & 40 \\
$>0.5$ and $<1 \mathrm{D}$ & 46 & 62 \\
1-2D & 24 & 58 \\
\hline
\end{tabular}

Table 3: Percentage of patients with postoperative astigmatism in group $A$ and $B$

\begin{tabular}{|c|c|c|}
\hline \multirow[t]{2}{*}{ Cylindrical power } & Group A (\%) & Group B (\%) \\
\hline & $\mathrm{N}=\mathbf{5 0}$ & $\mathrm{N}=\mathbf{5 0}$ \\
\hline & No.(\%) & No.(\%) \\
\hline OD & 4 & 0 \\
\hline $0-0.5 \mathrm{D}$ & 64 & 2 \\
\hline$\leq 1 \mathrm{D}$ & 30 & 40 \\
\hline $1-2 D$ & 2 & 58 \\
\hline
\end{tabular}

Net change in corneal astigmatism after MSICS and Phacoemulsification were 0.91D and 0.34D respectively (fig. 2).

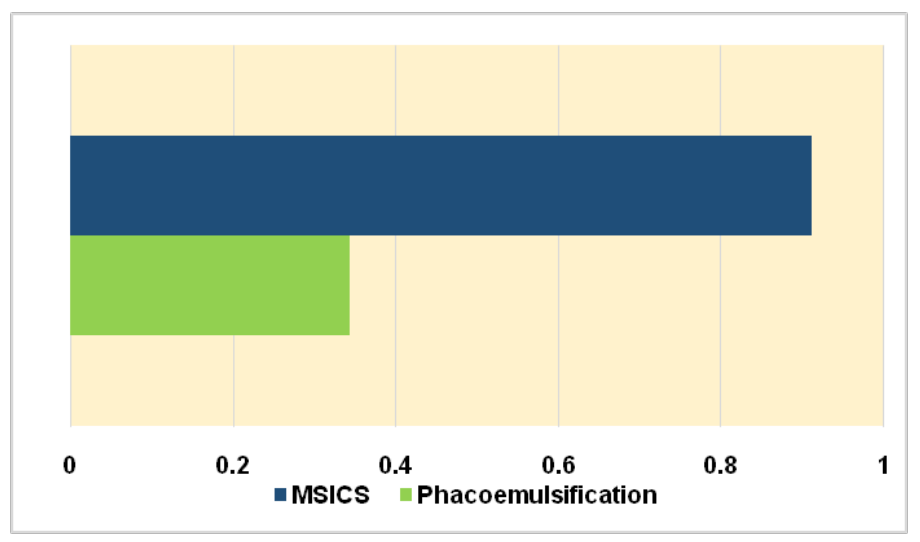

Fig. 2: Net induced postoperative corneal astigmatism in MSICS and phacoemulsification 
In Group B there was no improvement in astigmatic status of patients with preoperative astigmatism. Whereas in Group A patients, $38 \%$ showed mean improvement of $0.35 \pm 0.13 \mathrm{D}$ and $62 \%$ reported an increase in cylindrical power of $0.34 \pm 0.10 \mathrm{D}$. According to the independent $t$ test, data is statistically significant as $p$ is $0.00000003(\mathrm{p}<0.05)$ (table 4$)$. The mean value of net induced postoperative corneal astigmatism due to MSICS is $0.91 \pm 0.255$ and from phacoemulsification is $0.34 \pm 0.110$.

Table 4: Results from independent $\mathrm{T}$ test

\begin{tabular}{lllll}
\hline & N (total=100) & Mean & Standard deviation & t critical \\
\hline MSICS & 50 & 0.910 & 0.255 & 1.996 \\
Phacoemulsification & 50 & 0.343 & 0.110 & 0.00000003 \\
\hline
\end{tabular}

Statistically significant as $\mathrm{p}<0.05$

\section{DISCUSSION}

The global burden of cataract is significantly contributed by its incidence in developing countries. The universal benchmark of its treatment is by way of phacoemulsification, however, due to high cost this is not always feasible in developing countries like India. Here large-scale eye camps are undertaken to treat cataract induced visual loss and impairment. In lieu of restraints in cost, time and resources available, manual small incision cataract surgery is alternatively provided by the government and other non-profit organisations. This procedure was found to produce comparable improvement in visual acuity, to phacoemulsification, at a significantly lower cost, shorter duration and with less dependence on technology [6].

The main drawback of MSICS is the large incision size resulting in significant postoperative astigmatism. In recent years surgeons have come to favour smaller incisions and temporal incisions to superior ones to reduce surgically induced astigmatism. It was observed that $6 \mathrm{~mm}, 6.5 \mathrm{~mm}$ and $7 \mathrm{~mm}$ incisions induced $0.6+0.3 \mathrm{D}, 0.75+0.67 \mathrm{D}$ and $1.36+0.77 \mathrm{D}$ of astigmatism respectively [7].

In our study postoperative corneal astigmatism at 3 mo was found to be $0.91 \pm 0.110$ in MSICS and $0.34 \pm 0.255$ in phacoemulsification using $5.5 \mathrm{~mm}$ superior incision and $2.8 \mathrm{~mm}$ superotemporal incision, respectively. Group A observed $38 \%$ of patients had $0.35 \pm 0.13 \mathrm{D}$ of improvement in pre-operative astigmatism. Mean difference between group A and group B is 0.57D.

A study by Bhandari recorded mean postoperative astigmatism at $6^{\text {th }}$ week as 1.12D in the MSICS group and $0.64 \mathrm{D}$ in the Phacoemulsification group [8].

A study by Taneja, found patients having preoperative astigmatism less than 1 Diopter, the use of steep axis incisions during phacoemulsification was useful in reducing degree of astigmatism by 0.25-0.75D [9].

Sharma $\mathrm{N}$ observed mean postoperative corneal astigmatism using temporal incision to be $1.08 \pm 0.55 \mathrm{D}$ in MSICS group and $0.78 \pm 0.52 \mathrm{D}$ in the phacoemulsification group 1month postoperatively [10]. Results of group B of our study using a superior incision were comparable with their Sharma $\mathrm{N}$ et al. and Bhandari et al.

A similar study performed 3 mo postoperatively where recorded mean postoperative astigmatism due to phacoemulsification was $1.23 \pm 0.32 \mathrm{D}$ and MSICS was $1.27 \pm 0.22 \mathrm{D}$ [11]. This was not in concordance with our findings, which found a statistically significant difference between induced astigmatism in both procedures.

Gokhale stated that a superior incision in MSICS may be used to neutralise pre-existing ATR astigmatism of $1.25 \mathrm{D}$, as the incision is likely to induce $1.28 \mathrm{D}$ astigmatism according to centroid [12]. Our study showed no such improvement in preoperative astigmatic status of patients in group $B$.

The study agrees with the study by Daule where temporal incision in phacoemulsification induced $0.33 \pm 0.25 \mathrm{D}$ astigmatism 1 mo postoperatively [13]. Similar results were obtained in group A of our study.

Tejedor's study observed in patients with less than 0.75D of astigmatism $2.8 \mathrm{~mm}$ temporal incisions were preferable, producing mean astigmatism of $0.25 \mathrm{D}$ [14]. Our study found similar results in
Group A (table 4), where 74\% of patients had less than 0.5D of preoperative astigmatism (table 1).

The difference in degree of astigmatism induced by MSICS and phacoemulsification using superior incision and superotemporal incisions were statistically significant. The mean difference between induced postoperative corneal astigmatism between both groups is $0.57 \mathrm{D}$. This is considered a negligible difference that does not absolve the cost of a technologically advanced procedure. Instead postoperative astigmatism may be overcome with correction by means of spectacles.

In developing countries, especially in South East Asia, this procedure is of paramount importance in mitigating the effect of cataract on the incidence of preventable blindness.

The study conducted has several limitations. These include a) small sample size b) lack of data from $1^{\text {st }}, 7^{\text {th }}$, and $45^{\text {th }}$, postoperative days c) exclusion of patients with systemic diseases d) exclusion of patients with corneal disorders e) exclusion of patients having undergone previous ocular surgery.

While MSICS may produce greater surgically induced astigmatism, it should not be overlooked among ophthalmology post-graduates as it is useful to convert to in complicated Phacoemulsification procedures.

\section{CONCLUSION}

Significant statistical difference was found in postoperative corneal astigmatism after 3 mo follow up in both MSICS and phacoemulsification.

Mean postoperative astigmatism was found to be greater in superior incision MSICS than phacoemulsification.

Improvement in preoperative astigmatism was seen only in patients who underwent superotemporal incision phacoemulsification.

\section{FUNDING}

Nil

\section{AUTHORS CONTRIBUTIONS}

All the authors have contributed equally.

\section{CONFLICT OF INTERESTS}

\section{Declared none}

\section{REFERENCES}

1. World Health Organisation. Action plan for the prevention of avoidable blindness and visual impairment. Available from: https://www.iapb.org/wpcontent/uploads/ACTION_PLAN_WHA62-1-2009-

2013.pdf [Last accessed on 29 Jul 2020]

2. Minassian DC, Mehra V. 3.8 million blinded by cataract each year: projections from the first epidemiological study of incidence of cataract blindness in India. $\mathrm{Br} \mathrm{J}$ Ophthalmol 1990;74:341-3.

3. Murthy GVS, Jain BK, Shamanna BR, Subramanyam D. Improving cataract services in the Indian context. Community Eye Heal J 2014;27:4-5. 
4. Directorate General of Health Services. Available from: https://dghs.gov.in/content/1354_3_NationalProgrammeforCo ntrolofBlindnessVisual.aspx. [Last accessed on 10 Aug 2020]

5. Lamba PA, Sood NN. Changes of refraction after cataract surgery. Indian J Ophthalmol 1971;19:7-13.

6. Ruit S, Tabin G, Chang D. A prospective randomized clinical trial of phacoemulsification vs manual sutureless small-incision extracapsular cataract surgery in Nepal. Am J Ophthalmol 2007;143. DOI:10.1016/j.ajo.2006.07.023

7. Burgansky Z, Isakov I, Avizemer HBE. Minimal astigmatism after sutureless planned extracapsular cataract extraction. J Cataract Refract Surg 2002;28:499-503.

8. Bhandari A, Bhandari D. A randomized comparative study of visual outcome and complications following manual small incision cataract surgery and phacoemulsification. Indian J Clin Exp Ophthalmol 2019;5:539-42.

9. Taneja M. Management of astigmatism in cataract. Delhi Ophthalmol 2015;25:252-8
10. Sharma N, Vandana, Shinghal P. To compare postoperative astigmatism in temporal clear corneal incision phacoemulsification and temporal manual small incision cataract surgery. Indian J Clin Exp Ophthalmol 2017;3:177-9.

11. El-Sayed SH, El-Sobky HM, Badawy NM, El-Shafy EA Phacoemulsification versus manual small incision cataract surgery for treatment of cataract. Menoufia Med J 2015;28:1916.

12. Gokhale NS, Sawhney S. Reduction in astigmatism in manual small incision cataract surgery through change of incision site. Indian J Ophthalmol 2005;53:201-3.

13. Daule N, Tupe P. Comparision of keratometric astigmatism by phacoemulsification in superior scleral tunnel incision versus temporal clear corneal incision. Indian J Basic Appl Med Res 2018;1:420-8.

14. Tejedor J, Perez Rodriguez JA. Astigmatic change induced by 2.8-mm corneal Incisions for cataract surgery. Investigative Opthalmol Visual Sci 2009;50:989. 